\title{
Quantitative real time PCR analysis of apoptotic gene expression in chronic lymphocytic leukemia patients and their relationships with chemosensitivity
}

\author{
Hiwa K. Saaed ${ }^{1 *}$, Matin A. Mahmood ${ }^{1}$ and Najmaddin Khoshnaw ${ }^{2}$
}

\begin{abstract}
Background: Apoptosis-related gene expression such as BCL2, and p53 has been suggested in predicting the patient response to chemo- or radiotherapy, as well as patient's survival.

Methods: The aim of this study was to determine changes in BCL2 and p53 apoptosis related gene expressions in chronic lymphocytic leukemia (CLL) patients in response to different chemotherapy regimens and number of treatment courses. The study was conducted on $55 \mathrm{CLL}$ patients (44 CLL and $11 \mathrm{CLL} / \mathrm{SLL}$; small lymphocytic lymphoma) and 40 healthy individuals as control, over three-months period. The RNA was extracted by exploitation total RNA extraction kit, treated with DNAse, then CDNA was synthesized and qRT-PCR used to analyze antiapoptotic BCL2 and tumor suppresser p53 gene expressions.

Results: CLL/SLL showed higher BCL2 and p53 gene expression than CLL. The patients with CLL showed three-fold increase in BCL2 gene expression compared to healthy controls $(p<0.05)$, and $50 \%$ decrease in p53 gene expressions $(p<0.05)$. BCL2 gene expression was higher, particularly, for those who were treated with higher range of treatment courses and combination of fludarabine, cyclophosphamide and rituximab (FCR) regimen. P53 gene expression reciprocally related with $\mathrm{BCL} 2$ and vice versa.

Conclusions: In contrary to BCL2, p53 gene was extremely expressed in patients treated with chemotherapy agents, particularly after 24-30 months disease duration; suggesting a late expression of p53 during advanced stages of the disease. A proportional change in BCL2 and p53 gene expression was reported with different treatment regimens; Chlorambucil (Clb) decreased and FCR regimen increased BCL2 gene expression. Higher p53 gene expression reported with the Chlorambucil + (Chlorambucil + Prednisolone) regimen.
\end{abstract}

Keywords: RT-PCR, Apoptosis, p53, BCL2, Leukemia, CLL, Cancer, Chemotherapy

\section{Background}

Chronic Lymphocytic leukemia (CLL) is a disease of morphologically mature, but immunologically less mature lymphocytes manifested by progressive accumulation of these cells within the blood, bone marrow, and lymphatic tissues poignant in the main older population [1].

\footnotetext{
* Correspondence: hiwa.saaed@univsul.edu.iq

${ }^{1}$ Department of Pharmacology and Toxicology, School of Pharmacy, Faculty of Medical Sciences, University of Sulaimani, Post Box 402, Sulaymaniyah, Kurdistan, Iraq

Full list of author information is available at the end of the article
}

Hematological malignancies have been reported in high rates among countries of Asia including Kurdistan as a region of Iraq [2]. While within the Western World, CLL have been rated as the most prevalent adult malignant neoplastic disease with an incidence of $4.2 / 100000 /$ year [3].

Apoptosis is a cellular mechanism used to remove cells that are damaged, infected, or have reached the end of their lifecycle [4]. Interrupted control of apoptosis can cause many diseases, including cancer, autoimmune diseases, and degenerative disorders [5]. The ultimate role of the anti-apoptotic protein BCL2 is to intercept the 
action of pro-apoptotic proteins responsible for stoma formation within the mitochondria $[6,7]$. The vital equilibrium that exists between anti-apoptotic members such as BCL2, and pro-apoptotic members aids to dictate whether the cell initiates apoptosis [8,9].

Preclinical studies demonstrates that BCL2 has a mechanistic part in many conventional modes of cancer treatment [10-14] and its knockdown may potentiate the chemotherapy $[15,16]$. BCL2 has also been involved in promoting resistance to traditional therapies in preclinical models $[8,17,18]$. Constitutively higher expression of the BCL2 gene makes CLL cells more resistant to apoptosis, resulting in the accumulation of long-lived, clonal lymphocytes which characterizes the disease [19]. The treatment of relapsed chronic lymphocytic leukemia (CLL) has recently changed with the introduction of drugs that inhibit intracellular B-cell receptor signaling [20].

Selective targeting of BCL2 with ABT-199/venetoclax provided an acceptable safety profile and induced valuable outcomes in patients with relapsed CLL or SLL, including those with poor prognostic features [21].

Having a major role in cellular response to stress, p53 perform as the major barrier for tumorogenesis [22]. This impediment should be eliminated in order to allow tumor development. Indeed, nearly more or less than half of human cancers bear p53 gene mutations; in the majority of remaining cancer patients, p53 task is compromised by different mechanisms [23].

The current study aimed to analyze, BCL2 and p53 genes expression in CLL patients regarding chemotherapeutic regimen, number of treatment courses and disease states watch \& wait (WW), newly diagnosed (ND) and chemotherapy (CHT).

\section{Methods}

The study was conducted on 55 CLL patients visiting Hiwa Hospital for Hematology \& Oncology in Sulaimaniyah, Iraq, either for diagnosis, to continue the CHT courses or changes in their disease state, over threemonths period from 1st October to 30th December2013. Diagnosis and staging were based on standard clinical, morphological and immunophenotyping criteria. Detailed information was taken directly from the patient, or from the data in computer-based patient records.

The present study was carried out in four steps: Step I: Collecting blood samples from CLL patients and 40 healthy individuals as control. Step II: Total RNA was extracted from peripheral blood by total RNA isolation kit from Geneaid $^{\text {Tw }}$ (Geneaid Biotech Ltd., Taiwan) according to manufacturer's instruction in Kurdistan Institution for Strategic Studies and Scientific Research (KISSR) in Sulaimaniyah. Step III: cDNA was synthesized in Shiraz Institute for Cancer Research/Shiraz Medical College/Iran by Thermo Scientific Maxima $\mathrm{H}$ Minus
First Strand cDNA Synthesis Kit with dsDNAse according to manufacturer's instruction. Step IV: qRTPCR analysis was processed in 48 well StepOne ${ }^{\text {TM }}$ Real-Time PCR System from Applied Biosystems (Thermo Fisher Scientific, Waltham, MA USA) in Shiraz Institute for Cancer Research/Shiraz Medical College/Iran. TaqMan master mix was used for BCL2 and SYBR green for $\mathrm{p} 53$; using B-actin as internal control normalized gene expression.

\section{QRT-PCR data analysis}

Quantitative analysis was performed by the measurement of threshold cycle (CT) values during the exponential phase of amplification. $\triangle \mathrm{CT}$ was calculated by the difference between the CT values of the BCL2, p53 and the CT value of B-actin gene. Finally Relative quantifications were calculated by using this equation: $2-\Delta \mathrm{CT} /$ [Average of $(2-\Delta \mathrm{CT})$ ].

\section{Statistical analysis}

The results are expressed as mean \pm SEM. Independent student's $t$-test was used to analyze statistical differences between the means of gene expressions in CLL patient (treated and untreated) and control. One-way analysis of variance (ANOVA) test was used for comparison the difference in BCL2 and p53 gene expressions among patients with different disease states (WW, ND and $\mathrm{CHT}$ ), with different age, disease duration and frequency of treatment course. When appropriate, the LSD (least significant difference) test was used for multiple comparisons between groups. The threshold for significant difference was set at $P<0.05$. SPSS ${ }^{\circledR} 21$ software (SPSS Inc., Chicago, IL, USA) was used to carry out the statistical analyses.

\section{Results}

Gene expressions in patients and control groups

The relative BCL2 gene, $(6.1 \pm 1.3)$, was significantly increased $(p<0.05)$ in CLL patient (treated and untreated, $n=55)$ in comparison to control group $(n=40)$, $(0.85 \pm 0.1)$. The relative $\mathrm{p} 53$ gene expression was significantly decreased $(p<0.05)$ in CLL patient $(0.2 \pm 0.04)$ in comparison to control (0.9 \pm 0.2$)$, (Fig. 1$)$.

BCL2 and p53 gene expressions in patients with different disease states (WW, ND and CHT)

Comparison of the relative BCL2 gene expression in patients with (WW) $(n=3),(4.6 \pm 0.34)$, (ND) $(n=4)$ $(14.6 \pm 10.9)$ and $(\mathrm{CHT})(n=48)(5.5 \pm 1.2)$ showed no significant differences between different disease states (Fig. 2). The relative p53 gene expression in patients with (WW) $(n=3), \quad(0.08 \pm 0.01) \quad(\mathrm{ND})(n=4)(0.12 \pm$ $0.08)$ and $(\mathrm{CHT})(n=48)(0.2 \pm 0.04)$ showed no significant difference $\mathrm{F}(2,52)=0.69 ; P>0.05$, (Fig. 3 ). 


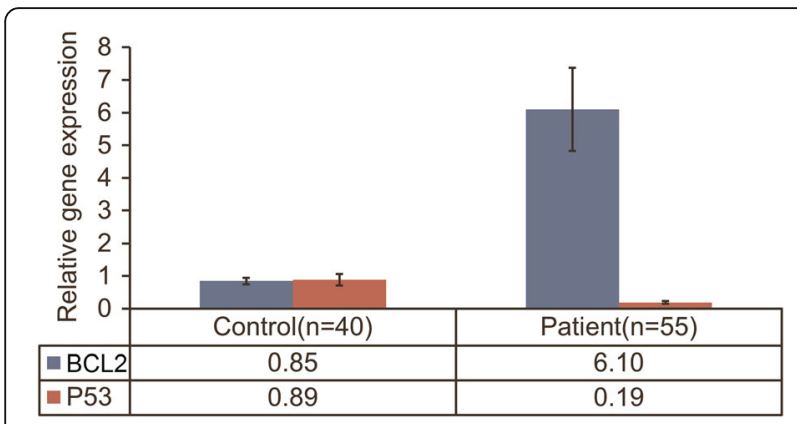

Fig. 1 Relative $\mathrm{BCl}-2$, p53 gene expression in CLL patients (treated and untreated) and control group, data expressed as Mean \pm SEM

The effect of age on gene expression

Analysis of BCL2 gene expression according to the age of the patients (treated and untreated) showed no significant difference $F(4,50)=1.14, p>0.05$. The $($ Mean \pm SEM) values for age groups were as follow: (40-49) [2.3 \pm 0.72 ], (50-59) [2.03 \pm 0.9$],(60-69)$ [6.79 \pm 2.56$],(70-79)$ [9.8 \pm 2.4], (80-91) [5.02 \pm 1.9$]$.

There was no significant difference for p53 $\mathrm{F}(4,50)=$ $0.1 .916, p>0.05$. The (Mean \pm SEM) values for age groups were as follow: (40-49) [0.13 \pm 0.07$],(50-59)$ [0.07 \pm 0.04$],(60-69)[0.18 \pm 0.04],(70-79)[0.4 \pm 0.13]$, (80-91) [0.1 \pm 0.07$]$.

\section{The difference in gene expression between genders}

Female $(n=19)(6.03 \pm 1.52)$ showed higher BCL2 gene expression than male $(n=36)(3.35 \pm 0.89)$ however, not significant $(P>0.05)$. In addition, no significant difference in p53 gene expression existed between male $[0.55 \pm 0.1]$ and female $[0.19 \pm 0.09)$; nevertheless, p53 in male showed higher gene expression than female.

\section{The difference in gene expression among control, CLL} and CLL/SLL

The comparison of gene expression between control group $(n=40)$, CLL $(n=44)$ and CLL/SLL $(n=11)$ showed a significant increase $(p<0.05)$ in BCL2 expression F

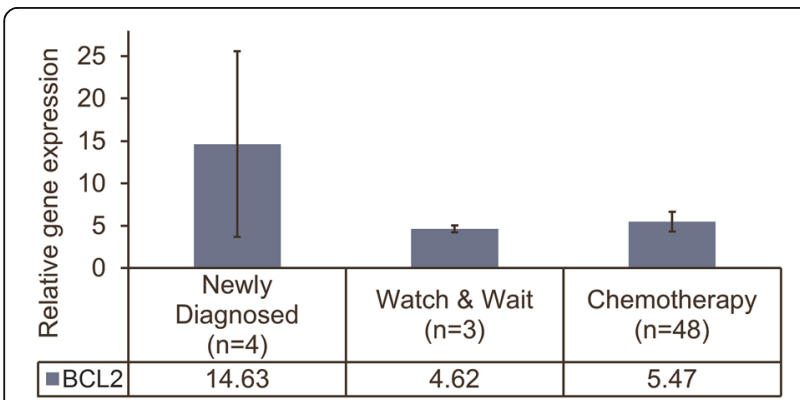

Fig. 2 Relative $\mathrm{BCl}-2$ gene expression in CLL/SLL patients in different disease states, data expressed as Mean \pm SEM

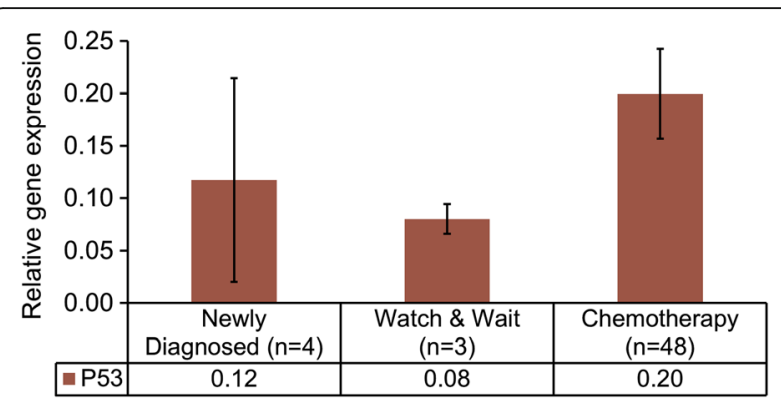

Fig. 3 Relative p53 gene expression in CLL/SLL patients in different disease states, data expressed as Mean \pm SEM

$(2,92)=8.93 p<0.05$, and a significant decrease in p53 expression $\mathrm{F}(2,92)=9.86$.

Multiple comparisons showed a significant difference in BCL2 gene expression between control $(0.85 \pm 0.1)$ and CLL patients' $(5.03 \pm 1.3) p<0.05$. There was a significant difference $(p<0.05)$ in gene expression between control $(5.03 \pm 1.3)$ and CLL/SLL patients $(10.3 \pm 3.6)$. In addition, the relative gene expression in CLL patients' gene $(5.03 \pm 1.3)$ was significantly less than that in CLL/ SLL patients' (10.3 \pm 3.6$)$ (Fig. 4).

For p53 gene expression, there were significant differences $(p<0.05)$ between control $(0.89 \pm 0.18)$ and CLL patients' $(0.14 \pm 0.03) p<0.05$, and control and CLL/ SLL patients' $(0.36 \pm 0.15)$. However, comparison between CLL $(0.14 \pm 0.03$ and CLL/SLL patients' $(0.36 \pm$ $0.15)$ showed no significant difference in $\mathrm{p} 53$ gene expression; (Fig. 5).

\section{The effect of number of treatment courses on gene expression}

BCL2 gene expression increased in response to an increase in number of treatment courses, however the increment in BCL2 gene expression within the treatment courses was no significant $F(7,46)=1.466$. No significant difference for p53 gene expression was reported $F(7,46)=2.3$, (Table 1$)$.

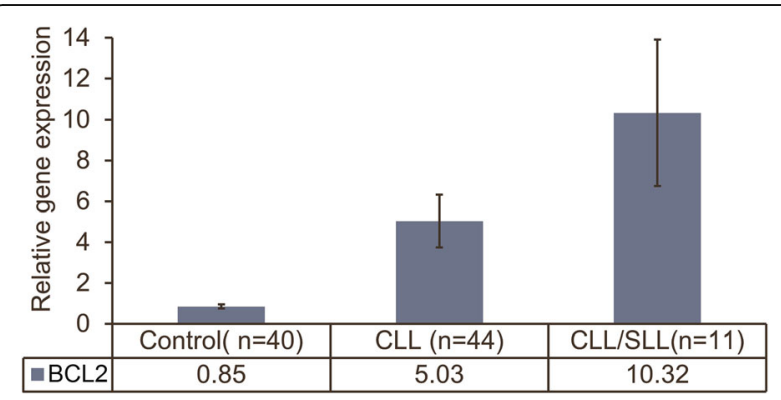

Fig. $4 \mathrm{BCl}-2$ gene expression among control, CLL and CLL/SLL patients, data expressed as Mean \pm SEM 


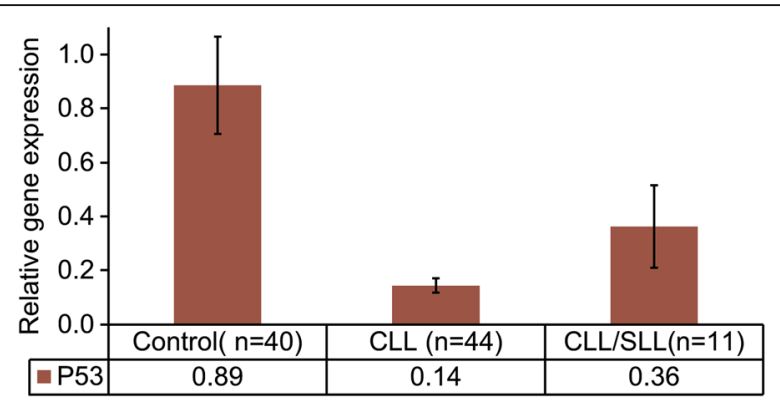

Fig. 5 p53 gene expression among control, CLL and CLL/SLL patients, data expressed as Mean \pm SEM

The effect of treatment regimen on gene expression ANOVA test was used to measure the difference in gene expressions between the patients who were treated with different regimens. Both BCL2 and p53 gene expression showed no significant difference $\mathrm{F}(6,40)=1.01 ; P>0.05$, $\mathrm{F}(6,40)=1.02 ; P>0.05$, respectively (Table 2 ).

As indicated in Table 2, Clb showed apoptotic activity by decreasing BCL2 gene expression while in FCR regimen the BCL2 gene expression was higher than other treatment regimens. For p53 gene expression, the $\mathrm{Clb}$ $+(\mathrm{Clb}+\mathrm{P})$ regimen showed higher $\mathrm{p} 53$ gene expression than other regimens.

\section{The effect of disease duration on gene expression}

Gene expression for BCL2 and p53 showed no significant difference $F(8,46)=1.156 ; F(8,46)=0.936$ (Table 3).

The results highlighted that newly diagnosed patients had higher BCL2 gene expression compared with other disease durations. Higher gene expression was reported for p53 for 24-30 months disease duration.

\section{Correlations between chemotherapy treatment and} number of treatment courses and gene expressions A Pearson's product-moment correlation was run to assess the relationship between the type of chemotherapy regimen and number of treatment courses and relative

Table 1 Relative gene expression of BCL2 and p53 of CLL patients (treated only) according to No. of treatment courses, data expressed as Mean \pm SEM

\begin{tabular}{llrrrr}
\hline $\begin{array}{l}\text { No. of } \\
\text { courses }\end{array}$ & $\begin{array}{l}\text { No. of } \\
\text { Patients }\end{array}$ & BCL2 expression & $P$ value & P53 expression & $P$ value \\
\hline $1-5$ & 6 & $2.20 \pm 1.07$ & 0.073 & $0.04 \pm 0.02$ & 0.578 \\
$6-10$ & 13 & $4.55 \pm 2.01$ & 0.607 & $0.22 \pm 0.07$ & 0.450 \\
$11-15$ & 12 & $3.12 \pm 1.58$ & 0.843 & $0.13 \pm 0.04$ & 0.939 \\
$16-20$ & 8 & $4.98 \pm 2.19$ & 0.578 & $0.11 \pm 0.05$ & 0.961 \\
$21-25$ & 4 & $11.27 \pm 5.41$ & 0.133 & $0.7 \pm 0.36$ & 0.071 \\
$26-30$ & 3 & $15.46 \pm 9.98$ & 0.274 & $0.2 \pm 0.10$ & 0.652 \\
$>30$ & 3 & $7.46 \pm 6.38$ & 0.422 & $0.3 \pm 0.21$ & 0.400 \\
\hline
\end{tabular}

Table 2 Relative gene expression of BCL2 and p53 of CLL patients (treated only) according to different treatment regimens, data expressed as Mean \pm SEM

\begin{tabular}{llllll}
\hline $\begin{array}{l}\text { Treatment } \\
\text { Regimen }\end{array}$ & $\begin{array}{l}\text { No. of } \\
\text { Patients }\end{array}$ & $\begin{array}{l}\text { BCL2 } \\
\text { expression }\end{array}$ & $P$ value & $\begin{array}{l}\text { P53 } \\
\text { expression }\end{array}$ & $P$ value \\
\hline $\mathrm{Clb}$ & 5 & $1.7 \pm 0.93$ & .338 & $0.12 \pm 0.05$ & 0.647 \\
$\mathrm{Clb}+\mathrm{P}$ & 10 & $4.2 \pm 1.42$ & .542 & $0.12 \pm 0.05$ & 0.583 \\
$\mathrm{Clb}+(\mathrm{Clb}+\mathrm{P})$ & 6 & $7.5 \pm 4.16$ & .972 & $0.45 \pm 0.27$ & 0.162 \\
$\mathrm{FCR}$ & 11 & $11.5 \pm 4.89$ & .402 & $0.20 \pm 0.06$ & 0.977 \\
$\mathrm{FCR}+\mathrm{Clb}+(\mathrm{Clb}+\mathrm{P})$ & 5 & $4.1 \pm 1.85$ & .592 & $0.08 \pm 0.04$ & 0.50 \\
$\mathrm{FCR}+(\mathrm{Clb}+\mathrm{P})$ & 4 & $1.6 \pm 0.71$ & .371 & $0.23 \pm 0.17$ & 0.903 \\
\hline $\mathrm{Clb}$ chlorambucil, $P$ prednisolone, $F C R: F$ fludarabine, C cyclophosphamide, \\
$R$ rituximab
\end{tabular}

gene expression. The correlations were statistically not significant, $p$ value $>0.05$. (Table 4 )

\section{Discussion}

The present study showed that in healthy subjects BCL2 and p53 expression by B-lymphocytes seem to be inversely related. Conversely, anti apoptotic activity expressed by BCL2 gene and tumor suppressor activity represented by p53 gene expression, were in a balanced state. A threefold increase of BCL2 expression and a 50\% decrease in p53 expression was reported in CLL patients. The finding is in agreement with Klobusická et al. [24], indicating an overexpression of that P53 protein and down regulation of BCL2 expression in a subgroup of B-CLL patients.

In ND patients the BCL2 and p53 gene expression were higher than that in patients who were underwent treatment with CHT. This is in line with Lazaridou et al. [25] suggesting an early overexpression of BCL2 and expression of p53 during advanced stages of the disease.

In contrary, patients in WW state showed lower BCL2 expression than ND patients and CHT patients and this partly explain why WW patients were asymptomatic. A relative expression of p53 with BCL2 gives evidence the cells still living in a balanced state, which may become disrupted in future by several predisposing factors.

Table 3 Relative BCL2 and p53 gene expression in CLL patients (treated and untreated) according to disease duration from diagnosis date, data expressed as Mean \pm SEM

\begin{tabular}{llllll}
\hline $\begin{array}{l}\text { Duration of } \\
\text { disease }\end{array}$ & $\begin{array}{l}\text { No. of } \\
\text { Patient }\end{array}$ & $\begin{array}{l}\text { BCL2 } \\
\text { expression }\end{array}$ & $P$ value & P53 expression & $P$ value \\
\hline ND & 3 & $19.3 \pm 14.0$ & 0.054 & $0.16 \pm 0.15$ & 0.80 \\
6 months & 10 & $5.2 \pm 2.29$ & 0.418 & $0.11 \pm 0.05$ & 0.983 \\
7-12 months & 6 & $1.3 \pm 0.69$ & 0.718 & $0.15 \pm 0.12$ & 0.995 \\
18 months & 9 & $6.7 \pm 2.66$ & 0.532 & $0.16 \pm 0.06$ & 0.789 \\
$19-24$ months & 7 & $2.3 \pm 0.86$ & 0.656 & $0.10 \pm 0.04$ & 0.143 \\
24-30 months & 7 & $7.2 \pm 3.56$ & 0.559 & $0.45 \pm 0.23$ & 0.781 \\
$31-36$ months & 7 & $7.8 \pm 4.74$ & 0.864 & $0.21 \pm 0.05$ & 0.896 \\
>36 months & 6 & $6.0 \pm 3.15$ & 0.573 & $0.18 \pm 0.10$ & 0.763 \\
\hline
\end{tabular}


Table 4 Correlation among BCL2 and p53 gene expression in CLL patients (treated only) according to number of treatment courses and type of treatment regimen

\begin{tabular}{|c|c|c|c|c|}
\hline & & & $\mathrm{BCL2}$ & P53 \\
\hline \multirow[t]{4}{*}{1.} & $\mathrm{Clb}$ & & & \\
\hline & & Pearson Correlation & -0.230 & 0.202 \\
\hline & & Sig. (2-tailed) & 0.661 & 0.701 \\
\hline & Treatment Courses & N & 6 & 6 \\
\hline \multirow[t]{4}{*}{2.} & $\mathrm{Clb}+\mathrm{P}$ & & & \\
\hline & & Pearson Correlation & 0.323 & -0.260 \\
\hline & & Sig. (2-tailed) & 0.333 & 0.440 \\
\hline & Treatment Courses & $N$ & 11 & 11 \\
\hline \multirow[t]{4}{*}{3.} & $\mathrm{Clb}+(\mathrm{Clb}+\mathrm{P})$ & & & \\
\hline & & Pearson Correlation & -0.049 & -0.760 \\
\hline & & Sig. (2-tailed) & 0.938 & 0.136 \\
\hline & Treatment Courses & $N$ & 5 & 5 \\
\hline \multirow[t]{4}{*}{4.} & FCR & & & \\
\hline & & Pearson Correlation & -0.854 & -0.491 \\
\hline & & Sig. (2-tailed) & 0.146 & 0.509 \\
\hline & Treatment Courses & $\mathrm{N}$ & 4 & 4 \\
\hline \multirow[t]{4}{*}{5.} & $\mathrm{FCR}+\mathrm{Clb}+(\mathrm{Clb}+\mathrm{P})$ & & & \\
\hline & & Pearson Correlation & 0.717 & -0.621 \\
\hline & & Sig. (2-tailed) & 0.173 & 0.264 \\
\hline & Treatment Courses & $\mathrm{N}$ & 5 & 5 \\
\hline \multirow[t]{4}{*}{6} & $\mathrm{FCR}+(\mathrm{Clb}+\mathrm{P})$ & & & \\
\hline & & Pearson Correlation & -0.452 & -.023 \\
\hline & & Sig. (2-tailed) & 0.190 & 0.951 \\
\hline & Treatment Courses & $\mathrm{N}$ & 10 & 10 \\
\hline
\end{tabular}

Age has an effect on p53 gene expression, younger patients showed normal levels with a decrease at the start of the treatment and an increase in older patients. This is in agreement with the study carried out by Stoklosa and Golab [26] which involved investigating several types of cancer with the finding that p53 gene is a potentially useful biomarker for predicting prognosis and patient's response to therapy

Gender has an effect on apoptosis gene expression, so that expression of BCL2 gene was reported to be higher and p53 was lower in female compared to male. Dissimilarities in gene expression between genders this result is similar to study results done by Klobusická M. and colleagues[27] which they reported that the expression of BCL2 protein was significantly higher in female patients under 50 years and inverse relationship between a higher accumulation of p53 and repressed BCL2 expression and vice versa was observed.

BCL2 gene expression in CLL and CLL/SLL was higher than healthy subject. Comparison of individual expression indicated that gene expression was higher in many CLL/SLL patients than CLL patients, which might explain the resistance to CHT. Although CLL and SLL do vary slightly, the cell of origin in CLL and CLL/SLL is identical and they have the same genetic pattern, morphology and prognostic markers. However, their survival and response to treatment tend to be very similar [28]. Expression of p53 gene was lower in CLL and CLL/ SLL compared to the control group, however, the difference was not statistically significant. Similarly, Santos et al. [29] reported that both CLL and CLL/SLL are currently considered different manifestations of the same entity in the fourth edition of the World Health Organization Classification of Tumours of Haematopoietic and Lymphoid Tissues. It is suspected that differential expression of chemokine receptors (e.g., reduced expression of R1 and CCR3 in SLL cells), integrins (e.g., CLL cells have lower expression of integrin $\alpha L \beta 2$ ), and genetic abnormalities (a higher incidence of trisomy 12 and lower incidence of $\operatorname{del}(13 q)$ is found in CLL/SLL) may explain some of the clinical differences between these two disorders [29].

The study showed proportional increase in BCL2 gene expression with patients' treatment regimens, whereas treatment courses were not directly affecting patients' gene expression. In contrary, this increase gives more imbalances between pro and anti-apoptotic activity to Bcells. Expression of p53 gene was not changed during treatment courses except for patients who took about 2125 courses and this might be due to the high proliferation activity of the B-cells at this stage of the disease that gives little higher gene expression in comparison with other treatment courses. The results of high expression of BCL2 in patients with high treatment courses or with long disease durations is similar to study results done by Reed JC [30] he reported that the overexpression of BCL2 is associated with tumor development or progression, and resistance to anticancer chemo- and radiotherapy and disagrees with studies done by Aguilar-Santelises et al. [31] they reported an early overexpression of BCL2 and expression of p53 during advanced stages of the disease.

For treatment regimens, $\mathrm{Clb}$ showed its effect on the apoptotic activity by decreasing the BCL2 gene expression. The study results are in agreement with a Pepper C. and colleagues [32] who reported that high levels of BCL2 in B-CLL cells were down-regulated in apoptotic cells after Clb treatment, however, the mean BCL2 expression in viable cells was increased. This was explained to be the result of the loss of lower BCL2-expressing cells into the apoptotic compartment. Clb alone or plus p shows slightly increase in p53 gene expression. This result agrees with the study carried out by Begleiter et al. [33], which reported that $\mathrm{Clb}$, similarly to purine nucleoside, might induce cell death in CLL by the p53dependent pathway. 
For other treatment regimens p53 gene expression showed no significant changes, which may indicate that such treatment, were not directly affecting the p53 cellular activity and/or FCR may not be the most appropriate therapy. This assumption is supported by Hillmen et al. [34], who reported that patients with abnormalities of the p53 pathway have a very poor response to FCR (5\% complete remissions in 17p-deleted CLL compared with nearly $50 \%$ for those patients without $17 \mathrm{p}$ deletion). However, FCR regimen cause massive increase in BCL2 gene expression and this result disagrees with known mechanism of action of fludarabine, which triggers apoptosis and disagree with study carried out by Plosker and Figgitt [35]. They reported that rituximab sensitizes neoplastic cells to the effects of chemotherapeutic agents. Thus, supporting the use of combination of $\mathrm{CHT}$ with rituximab. So rituximab down regulates interleukin (IL)-10 and BCL2 expression, thus making neoplastic Bcells potentially more susceptible to fludarabine-induced apoptosis [36].

The combination $\mathrm{Clb}$ and $\mathrm{P}$ then FCR decreases BCL2 gene expression and this might be due to synergistic activity of the treatment combination, which triggers further apoptosis.

Results showed in ND patients the BCL2 gene expression is high. This decreases by starting $\mathrm{CHT}$ at low levels in first year of treatment due to effect of $\mathrm{CHT}$ compared with ND. The expression of BCL2 fluctuated during different stages of treatment courses till two years into treatment. BCL2 showed almost constant expression after that period and this might be due to resistance to $\mathrm{CHT}$ that makes this straight expression. In comparison, p53 gene expression showed a straight expression during all stages of treatment courses giving evidence that it was not regulated by treatment.

Study results showed no statistically significant correlation between type of treatment and number of treatment courses with BCL2 and p53 gene expressions $p$ value $>0.05$ this result is similar to study results done by Cordone et al., they reported that in CLL the expression of the p53 protein, is strongly associated with p53 gene mutations, a morphological variant (CLL with $>10 \%$ prolymphocytes), advanced clinical stage, progressive disease, poor response to therapy, and short survival [37] and disagrees with Thomas A. and colleagues study results which reported by chlorambucil produced almost identical changes in BCL2 and Bax expression in normal T-cells and leukaemic B-cells triggered to die by apoptosis, which together with the correlation between BCL2 and chemosensitivity confirms a pivotal role for BCL2 in regulating a distal step in the apoptotic pathway following cytotoxic cellular damage [38] and also disagrees with data reported by Robertson LE and colleagues, their data suggests that
BCL2 is important in the pathogenesis and progression of CLL and that quantitation of BCL2 protein may provide useful prognostic information [39].

\section{Conclusions}

BCL2 gene expression was almost equal between the patients newly diagnosed and those underwent chemotherapy treatment. In contrary, p53 gene was extremely expressed in patients treated with chemotherapy agents particularly after 24-30 months disease duration; suggesting an early overexpression of BCL2 and expression of p53 during advanced stages of the disease.

Treatment courses were not directly affected patients' gene expression. However, a proportional change in BCL2 and p53 gene expression was reported with different treatment regimens; $\mathrm{Clb}$ decreased and FCR regimen increased BCL2 gene expression. Higher p53 gene expression reported with the $\mathrm{Clb}+(\mathrm{Clb}+\mathrm{P})$ regimen.

\section{Abbreviations \\ BCL2: B-cell lymphoma; cDNA: Complementary DNA; CHT: Chemotherapy; CLL: Chronic Lymphocytic Leukemia; Clb: Chlorambucil; DEPC: Diethylpyrocarbonate; dNTP: Deoxynucleotide; dsDNAse: Double- strand specific DNAse enzymes; FCR: Fludarabine Cyclophosphamide, Rituximab; KISSR: Kurdistan Institution for Strategic Studies and Scientific Research; ND: Newly Diagnosed; P: Prednisolone; qRT-PCR: Quantitative Real Time Polymerase Chain Reaction; RT-PCR: Real Time Polymerase Chain Reaction; SLL: Small Lymphocytic Lymphoma; TNF: Tumor necrosis factor; W \& W: Watch and wait}

\section{Acknowledgments}

We thank Prof. Ghaderi, Dr. Mahboubaba and Dr. Husseini, and other members at the Shiraz Institute for Cancer Research, Shiraz Medical College-University of Shiraz, Iran, for their collaborations. We thank Prof. Ferhad Barzangi and Dr. Zhala A.A. Karim at Institution for Strategic Studies and Scientific Research" in Sulaimaniyah for their instrumental contribution. Special thanks, to Dr. Banaz Mubarak at "Hiwa Hospital of Oncology \& Hematology in Sulaimaniyah" for her guidance through data collection. Financial support from

University of Sulaimani is acknowledged.

This paper is based on a MSc thesis by M.A.M.

Funding

Sources of funding for the research was from University of Sulaimani.

Availability of data and materials

Please contact corresponding author for data requests.

\section{Authors' contribution}

All authors discussed the research design and results at all stages. HKS and MAM designed and administered the experiment, analyzed and interpreted the data; and prepared the manuscript. MAM performed the experiments. HKS gave conceptual advice and final approval of the version to be published; NK prepared and managed the patients in Hiwa Hospital and gave clinical advice. All authors read and approved the final manuscript.

\section{Competing interests}

The authors declare that they have no competing interests.

\section{Consent for publication}

Not applicable.

\section{Ethics approval and consent to participate}

The study approved by Ethical Committee at the Faculty of Medical Sciences and Scientific Committee of Department of Pharmacology and Toxicology, School of Pharmacy, University of Sulaimani. 


\section{Capsule}

Anti-apoptotic BCl-2 family members and additionally the tumor suppresser p53 may be thought-about as a key choice of cancer and significantly contributes to the impact of current treatment modalities on cancer cells.

\section{Author details}

'Department of Pharmacology and Toxicology, School of Pharmacy, Faculty of Medical Sciences, University of Sulaimani, Post Box 402, Sulaymaniyah, Kurdistan, Iraq. ${ }^{2}$ Department of Hematology, Hiwa Hospital, Directorate of Health, Sulaymaniyah, Kurdistan, Iraq.

\section{Received: 9 September 2016 Accepted: 20 February 2017}

\section{Published online: 01 April 2017}

\section{References}

1. Dighiero G, Hamblin TJ. Chronic lymphocytic leukaemia. Lancet. 2008; 371(9617):1017-29.

2. Khoshnaw N, Mohammed HA, Abdullah DA. Patterns of cancer in Kurdistan - results of eight years cancer registration in sulaymaniyah provinceKurdistan-Iraq. Asian Pac J Cancer Prev. 2015;16(18):8525-31.

3. Altekruse SF, Kosary CL, Krapcho M, Neyman N, Aminou R, Waldron W, et al. SEER Cancer Statistics Review, 1975-2007. National Cancer Institute. 2010. Available from: http://seer.cancer.gov/csr/1975_2007/index.html. Accessed 7 Mar 2016.

4. Autret A, Martin SJ. Emerging role for members of the BCl-2 family in mitochondrial morphogenesis. Mol Cell. 2009:36(3):355-63.

5. Cory S, Adams JM. The BCl2 family: regulators of the cellular life-or-death switch. Nat Rev Cancer. 2002;2(9):647-56.

6. Llambi F, Moldoveanu T, Tait SWG, Bouchier-Hayes L, Temirov J, McCormick $L L$, et al. A unified model of mammalian $B C L-2$ protein family interactions at the mitochondria. Mol Cell. 2011:44(4):517-31.

7. Wei MC, Zong WX, Cheng EH, Lindsten T, Panoutsakopoulou V, Ross AJ, et al. Proapoptotic BAX and BAK: a requisite gateway to mitochondrial dysfunction and death. Science. 2001;292(5517):727-30

8. Strasser A, Cory S, Adams JM. Deciphering the rules of programmed cell death to improve therapy of cancer and other diseases. EMBO J. 2011 30(18):3667-83.

9. García-Sáez AJ. The secrets of the Bcl-2 family. Cell Death Differ. 2012;19(11):1733-40.

10. Pedersen IM, Buhl AM, Klausen P, Geisler CH, Jurlander J. The chimeric antiCD20 antibody rituximab induces apoptosis in B-cell chronic lymphocytic leukemia cells through a p38 mitogen activated protein-kinase-dependent mechanism. Blood. 2002;99(4):1314-9

11. Wang $M$, Han XH, Zhang L, Yang J, Qian JF, Shi YK, et al. Bortezomib is synergistic with rituximab and cyclophosphamide in inducing apoptosis of mantle cell lymphoma cells in vitro and in vivo. Leukemia. 2008;22(1):179-85.

12. Herman SEM, Gordon AL, Wagner AJ, Heerema NA, Zhao W, Flynn JM, et al. Phosphatidylinositol 3-kinase- $\delta$ inhibitor CAL-101 shows promising preclinical activity in chronic lymphocytic leukemia by antagonizing intrinsic and extrinsic cellular survival signals. Blood. 2010;116(12):2078-88.

13. Herman SEM, Gordon AL, Hertlein E, Ramanunni A, Zhang X, Jaglowski S, et al. Bruton tyrosine kinase represents a promising therapeutic target for treatment of chronic lymphocytic leukemia and is effectively targeted by PCl-32765, Blood. 2011:117(23):6287-96.

14. Platia J, Bucura O, Khosravi-Far R. Apoptotic cell signaling in cancer progression and therapy. Integr Biol. 2011;3(4):279-96.

15. Tse C, Shoemaker AR, Adickes J, Anderson MG, Chen J, Jin S, et al. ABT-263: a potent and orally bioavailable Bcl-2 family inhibitor. Cancer Res. 2008; 68(9):3421-8.

16. Tahir SK, Yang X, Anderson MG, Morgan-Lappe SE, Sarthy AV, Chen J, et al. Influence of BCl-2 family members on the cellular response of small-cell lung cancer cell lines to ABT-737. Cancer Res. 2007;67(3):1176-83.

17. Reed JC. BCl-2-family proteins and hematologic malignancies: history and future prospects. Blood. 2008;111(7):3322-30.

18. Stolz C, Hess G, Hähnel PS, Grabellus F, Hoffarth S, Schmid KW, et al. Targeting BCl-2 family proteins modulates the sensitivity of B-cell lymphoma to rituximab-induced apoptosis. Blood. 2008;112(8):3312-21.

19. Cimmino A, Calin GA, Fabbri M, lorio MV, Ferracin M, Shimizu M, et al. miR15 and miR-16 induce apoptosis by targeting BCL2. Proc Natl Acad Sci U S A. 2005;102(39):13944-9.
20. Advani RH, Buggy JJ, Sharman JP, Smith SM, Boyd TE, Grant B, et al. Bruton tyrosine kinase inhibitor ibrutinib (PCl-32765) has significant activity in patients with relapsed/refractory B-cell malignancies. J Clin Oncol. 2013; 31(1):88-94.

21. Roberts AW, Davids MS, Pagel JM, Kahl BS, Puvvada SD, Gerecitano JF, et al. Targeting BCL2 with venetoclax in relapsed chronic lymphocytic leukemia. N Engl J Med. 2016;374(4):311-22.

22. Haupt S, Berger M, Goldberg Z, Haupt Y. Apoptosis - the p53 network. J Cell Sci. 2003:116(Pt 20):4077-85.

23. Vogelstein B, Lane D, Levine AJ. Surfing the p53 network. Nature. 2000; 408(6810):307-10

24. Klobušická M, Kusenda J, Babušíková O. Immunocytochemical detection of bcl-2 and p53 proteins in B-chronic lymphocytic leukemia patients. Neoplasma. 2002;49(6):387-93.

25. Lazaridou A, Miraxtsi C, Korantzis J, Eleftheriadis N, Christakis Jl. Simultaneous detection of BCL-2 protein, trisomy 12 , retinoblastoma and P53 monoallelic gene deletions in B-cell chronic lymphocytic leukemia by fluorescence in situ hybridization (FISH): relation to disease status. Leuk Lymphoma. 2000;36(5-6):503-12.

26. Prospects for p53-based cancer therapy. [cited 2016 Apr 12]. Available from: http://www.actabp.pl/pdf/2_2005/321.pdf.

27. Klobusická M, Kusenda J, Babusíková O. Immunocytochemical detection of bcl-2 and p53 proteins in B-chronic lymphocytic leukemia patients. Neoplasma. 2002:49(6):387-93.

28. Morrison WH, Hoppe RT, Weiss LM, Picozzi VJ, Horning SJ. Small lymphocytic lymphoma. J Clin Oncol. 1989:7(5):598-606.

29. Santos FPS, O'Brien S. Small lymphocytic lymphoma and chronic lymphocytic leukemia: are they the same disease? Cancer J. 2013;18(5):396-403.

30. Reed JC. BCl-2 family proteins: regulators of apoptosis and chemoresistance in hematologic malignancies. Semin Hematol. 1997;34(4 Suppl 5):9-19.

31. Aguilar-Santelises $M$, Rottenberg ME, Lewin N, Mellstedt $H$, Jondal M. $\mathrm{BCl}-2, \mathrm{Bax}$ andp53 expression in B-CLL in relation toin vitro survival and clinical progression. Int J Cancer [Internet]. Wiley Subscription Services, Inc., A Wiley Company; 1996;69(2):114-9.

32. Pepper C, Thomas A, Hoy T, Bentley P. Chlorambucil resistance in B-cell chronic lymphocytic leukaemia is mediated through failed Bax induction and selection of high Bcl-2-expressing subclones. Br J Haematol. 1997; 104(3):581-8.

33. Begleiter A, Verburg L, Ashique A, Lee K, Israels LG, Mowat MR, et al. Comparison of antitumor activities of 2-chlorodeoxyadenosine and 9-betaarabinosyl-2-fluoroadenine in chronic lymphocytic leukemia and marrow cells in vitro. Leukemia. 1995;9(11):1875-81.

34. Hillmen P, Skotnicki AB, Robak T, Jaksic B, Dmoszynska A, Wu J, et al. Alemtuzumab compared with chlorambucil as first-line therapy for chronic Iymphocytic leukemia. J Clin Oncol. 2007:25(35):5616-23.

35. Plosker GL, Figgitt DP. Rituximab. Drugs. 2003;63(8):803-43. Springer International Publishing.

36. Alas S, Emmanouilides C, Bonavida B. Inhibition of interleukin ten by rituximab results in down-regulation of bcl-2 and sensitization of B-cell nonHodgkin's lymphoma to apoptosis. Clin Cancer Res. 2001;7(3):709-23.

37. Cordone I, Masi S, Mauro FR, Soddu S, Morsilli O, Valentini T, et al. p53 Expression in B-Cell Chronic Lymphocytic Leukemia: A Marker of Disease Progression and Poor Prognosis. Blood. 1998;91(11):4342-9.

38. Thomas A, Pepper C, Hoy T, Bentley P. BCl-2 and bax expression and chlorambucil-induced apoptosis in the T-cells and leukaemic B-cells of untreated B-cell chronic lymphocytic leukaemia patients. Leuk Res. 2000; 24(10):813-21

39. Robertson LE, Plunkett W, McConnell K, Keating MJ, McDonnell TJ. BCl-2 expression in chronic lymphocytic leukemia and its correlation with the induction of apoptosis and clinical outcome Leukemia 1996:10(3):456-9. 